\title{
$\mathrm{S}$ \\ Turismo e \\ Revista I UFPR
}

\section{Acessibilidade e Turismo no Centro Histórico de São Luís (Maranhão, Brasil)}

\author{
Accessibility and Tourism in the Historical Center of São Luís, \\ (Maranhão, Brazil)
}

\author{
Angela Roberta Lucas Leite ${ }^{1}$ \\ Rosélis Barbosa Câmara² \\ Yasmin Alessandra Lima da Silva ${ }^{3}$
}

RESUMO: A temática da acessibilidade ganhou espaço na pauta de discussão da sociedade nas últimas décadas e, apesar de algumas conquistas, ainda é necessário percorrer uma longa trajetória até que seja alcançado o princípio estabelecido na Constituição Federal Brasileira, previsto no art. $3^{\circ}$, inciso I, de uma sociedade livre, justa e igualitária para todos os cidadãos, indistintamente. Nesse sentido, o presente trabalho teve como objeto de estudo o turismo acessível no centro histórico de São Luís, lançando um olhar especificamente para o bairro histórico e turístico da Praia Grande. O objetivo foi analisar as condições de acessibilidade para cadeirantes em espaços e equipamentos públicos existentes no referido bairro, tendo a NBR 9050/2015

\footnotetext{
1 Mestrado em Políticas Públicas pela Universidade Federal do Maranhão (UFMA). Graduação em Hotelaria pela UFMA. Editora-chefe da revista Turismo \& Cidades. E-mail: angelarobertalucas@gmail. com

2 Doutorado em Linguística e Língua Portuguesa pela Universidade Estadual Paulista (UNESP). Mestrado em Comunicação pela Universidade Federal do Rio de Janeiro (UFRJ). Graduação em Turismo pela Universidade Federal do Maranhão (UFMA). Professora Associada I do Departamento de Turismo e Hotelaria da UFMA. E-mail: zelis.camara@hotmail.com

3 Graduação em Hotelaria (em andamento) pela Universidade Federal do Maranhão (UFMA). E-mail: yasminalessandra_@hotmail.com
} 
como princípio de análise. Para tanto, foram adotados procedimentos metodológicos de abordagem qualitativa, com etapa exploratória, durante a qual foram aplicados questionários às pessoas com deficiência (cadeirantes), além do método de observação empírica do local. A pesquisa apontou que a infraestrutura existente no bairro não é suficientemente adaptada para a realidade da pessoa com deficiência que utiliza cadeiras de rodas, violando, assim, a garantia de autonomia e seguridade a esse público.

Palavras-chave: Turismo; Inclusão; Acessibilidade; Centro Histórico; São Luís

ABSTRACT: The theme of accessibility has gained space in the discussion agenda of society in the recent decades and, despite some achievements, it is still necessary to go a long way until the established principle in the Brazilian Federal Constitution, provided for in art. 3, item I, of a free, fair and equal society for all citizens, without distinction. In this sense, the present study had as its object of study the accessible tourism in the historical center of São Luís, taking a specific look at the historical and tourist neighborhood of Praia Grande. The objective was to analyze the accessibility conditions for wheelchair users in public spaces and facilities in the historic and tourist district of mentioned neighborhood, using NBR 9050/2015 as the principle of analysis. To this end, methodological procedures with a qualitative approach were adopted, with an exploratory stage, during which questionnaires were given to people with disabilities (wheelchair users), in addition to the empirical observation method of the place. The research pointed out that the existing infrastructure in the neighborhood is not sufficiently adapted to the reality of people with disabilities who use wheelchairs, thus violating the guarantee of autonomy and security for this public.

Keywords: Tourism; Inclusion; Accessibility; Historic Center; São Luís 


\section{INTRODUÇÃO}

Os discursos acerca da inclusão ganharam força nas últimas décadas, especialmente partir dos anos de 1980 nos países ocidentais e passaram a permear a sociedade nos mais distintos setores (MAZZOTTA; ANTINO, 2011). Tais exposições se voltam, geralmente, para a construção de práticas inclusivas que visam à superação das desigualdades históricas e à garantia da inserção das pessoas com deficiência (PCD) no contexto da sociedade, não somente no âmbito familiar ou do trabalho, mas em qualquer arena social.

Falar sobre práticas inclusivas é trazer à tona ideais de uma sociedade mais justa e igualitária, em que "cada ator (poder público e político, universidades, sociedade civil, dentre outros) desempenhe seu papel na sociedade de forma atuante" (COELHO; GUIMARÃES, 2012, p. 10). Deste modo, esses atores sociais devem priorizar ideias e ferramentas relacionadas à inclusão social de forma que contribua para o desenvolvimento pessoal e social de um determinado grupo.

É nesse ínterim que o turismo, pensado enquanto atividade inclusiva por meio do lazer, possibilita o convívio com a diversidade, o encontro e a troca cultural entre vários atores sociais. A esse respeito, Pereira (2011, p. 256) enfatiza que o turismo "opera pela ruptura do isolamento, provocando o contato entre culturas e ocasionando interações de múltiplos e variados atores sociais". Pensar inclusão social no turismo, sobretudo para PCD, "significa promover alterações no espaço de modo a permitir que os equipamentos e serviços de turismo sejam utilizados com segurança e conforto por todos" (MACEDO, 2017, p.16), ou seja, significa pensar em um público significativo, mas ignorado por uma parcela do mercado. Conceber o turismo por essa acepção é entendê-lo como atividade voltada para o interesse e necessidade de inclusão - atividade essa capaz de se adequar às necessidades dos mais variados públicos e de toda a diversidade humana.

Para além da perspectiva social, partindo de uma ótica mercadológica, Kushano e Almeida (2008, p. 95) observam que "as ofertas de produtos e serviços turísticos para pessoas com necessidades especiais e mobilidade reduzida estão aumentando, inclusive no Brasil". Segundo esses autores, tal fato pode ser observado em algumas companhias aéreas brasileiras, "que proporcionam atendimento personalizado com equipes treinadas e orientadas para PPD1. Cadeiras de rodas especiais, cartilhas de emergência em braile, entre outras adaptações, são encontradas".

Desse modo, consumidores que antes permaneciam em torno dos seus ambientes habituais são motivados diariamente a buscar experiências em novos lugares. De acordo com Smith, Amorim e Soares (2013), a maioria desse público viaja acompanhado, o que representa um aumento significativo na geração de receita para a localidade visitada.

1 Nomenclatura para Pessoa Portadora de Deficiência utilizada por Kushano e Almeida (2008), em que os autores fundamentam a utilização deste termo a partir do Decreto 914, 06/09/1993, artigo 3은 (http://www.camara.gov.br/internet/infdoc/Publicacoes/html/pdf/LegPortDefinal.pdf). 
Diante desse cenário, e levando em consideração que os destinos turísticos - mais precisamente os centros históricos - devem ser dotados de infraestrutura acessível para todos os públicos, de forma a facilitar a interação entre turistas e autóctones, é que surge a seguinte indagação: a infraestrutura disponível no bairro Praia Grande, em São Luís, Maranhão (MA), é acessível para turistas/visitantes cadeirantes?

Sob esse cenário, teve-se como objetivo analisar as condições de acessibilidade para cadeirantes em espaços e equipamentos públicos existentes no bairro histórico e turístico da Praia Grande, em São Luís, MA, tendo a NBR 9050/2015² como princípio de análise.

A pesquisa encontra-se organizada da seguinte forma: na seção 1 apresentase a introdução, na seção 2 é exposto o diálogo necessário entre acessibilidade e atividade turística. Na seção 3 traz-se à tona a acessibilidade em centros históricos no Brasil, enquanto na seção 4 tem-se os procedimentos metodológicos. Os resultados e discussões compõem a seção 5 e por último, as considerações finais do trabalho.

\section{ACESSIBILIDADE E ATIVIDADE TURÍSTICA: UM DIÁLOGO NECESSÁRIO}

$\mathrm{Na}$ literatura, o termo inclusão possui diversos significados e sua abordagem teórica é bastante ampla. Em uma perspectiva social, inclusão significa, segundo o dicionário Michaelis (2020, s.p.), o "ato de trazer aquele que é excluído socialmente, por qualquer motivo, para uma sociedade que participa de todos os aspectos e dimensões da vida, isto é, dos âmbitos econômico, cultural, político, religioso etc".

Nos preceitos de Dias (2019, p.67), incluir significa "trazer para dentro o que está fora". Para essa autora, a inclusão remodela o processo de normalização social, que objetiva "trazer grupos minoritários para dentro de uma sociedade, reorganizando os lugares que esses sujeitos ocupam". Inclusão social refere-se, portanto, ao conjunto de ações direcionadas a grupos minoritários e vulneráveis ${ }^{3}$, que visa à inserção de todos os cidadãos de forma igualitária, de modo a garantir o pleno exercício da cidadania.

Já a acessibilidade como forma de inclusão significa "livre acesso, possibilidade de aproximação" (MICHAELIS, 2020, s.p.). Autores como Girle (2003, p.36) definem a acessibilidade como uma relação, sugerindo uma descrição de "ser visto". Em outras palavras, se algo é acessível é porque existe o contato simultâneo entre o ser vivo e o ambiente no qual ele se faz presente, o que o possibilita notar e ser notado, estabelecendo conexões mutuamente.

2 Esta norma estabelece critérios e parâmetros técnicos a serem observados quanto ao projeto, construção, instalação e adaptação do meio urbano e rural, e de edificações às condições de acessibilidade (ABNT, 2015, s.p.).

3 Compreende-se que ambos os termos têm em comum uma "estreita relação de afetamento no que tange ao poder que lhes é tirado, ao processo de dominação, à violência sofrida, à marginalização social e a uma necessidade premente de tolerância" (CARMO, 2016, pp. 203-204). 
Em se tratando da pessoa com deficiência, para assegurar a inclusão desta nas várias dimensões do seu ambiente, é necessária a participação de diversos setores da sociedade, como órgãos governamentais da esfera nacional, estadual e municipal, organizações privadas e sociedade civil. Nesse sentido, Costa (2008) pondera que a acessibilidade tem papel determinante no processo de inclusão das PCD e que a sua promoção deve ser um dos objetivos das sociedades que prezem pela solidariedade e pela integração, além do respeito pelas diferenças.

Conforme a Declaração dos Direitos Humanos (1948) e a Constituição Federal Brasileira (1988), todos têm direito à igualdade, à vida, à educação e à saúde. Logo, é dever do Estado atender ao interesse público, seja nas áreas de educação, saúde, mobilidade, cultura, lazer, e outras mais que sejam essenciais para a vida das pessoas.

É possível vislumbrar nesses documentos um discurso voltado para a valorização da vida de todos os cidadãos, o qual tem como fim a inserção social da pessoa com deficiência, objetivando transformá-la em sujeito de direitos (DIAS, 2019), participante e construtora de suas próprias histórias. Porém, embora sejam dotadas de direitos, ainda hoje PCD se deparam com preconceitos, invisibilidade social, barreiras que não são superadas apenas com normativas.

O estranhamento causado pela deficiência, como destaca Silva (2006, p. 426), "configura-se como um mecanismo de negação social, uma vez que suas diferenças são ressaltadas como uma falta, carência ou impossibilidade". Dessa forma, o preconceito, o distanciamento e a intolerância para com essas pessoas surgem em razão dos padrões físicos e intelectuais estabelecidos pela estrutura funcional da sociedade, que tende a excluir aqueles que são "diferentes", "imperfeitos", "improdutivos" e que venham a representar um obstáculo para a produção capitalista (SILVA, 2006). Entende-se, portanto, que o corpo assume uma posição relevante nessa sociedade, que busca a produtividade a qualquer custo, e aqueles que não se enquadram aos padrões são excluídos.

Contudo, entende-se que não se deve separar as pessoas por gênero, idade, cor ou condição física, social, intelectual, já que a inclusão social com cidadania engloba a participação dos indivíduos na condição de cidadão na sociedade, com os mesmos direitos e deveres nas mais diversas esferas da vida (trabalho, educação, lazer, política, cultura, entre outros). No Brasil, com os avanços das discussões a respeito da inclusão social e da melhoria da qualidade de vida desse segmento, outros temas começaram a ser englobados nessa análise, como é o caso do turismo.

Segundo Magalhães e Schueler (2020, p. 111) a discussão do turismo acessível se torna pertinente em nossa sociedade, uma vez que o turismo é uma atividade de bens e serviços e, como tal, necessita ser estruturada e aperfeiçoada para atender a demanda turística, ou seja, "é importante que as vias de acesso ao destino, bem como seu entorno e infraestrutura estejam adequadas para a pessoa com deficiência, pois o destino é o local onde as ações serão desenvolvidas".

No que diz respeito a esfera pública tem direcionado leis e normas que garantem o acesso e a proteção dos direitos das PCD à atividade turística, com 
o pleno exercício de sua autonomia e cidadania. É o caso da Lei no 13.146/2015, denominada Estatuto da Pessoa com Deficiência, que aborda a oferta de instalações hoteleiras com acessibilidade arquitetônica segura e confortável e com recursos humanos capacitados para atender a esse segmento (art. $45, \S 2$ ), a partir da instrução dos guias turísticos com informações voltadas para o atendimento de PCD ou com mobilidade reduzida (art. 52, inciso V, § 3o) e da sinalização, com vistas a orientar as pessoas de um modo geral quanto à acessibilidade aos espaços e quanto aos serviços disponíveis (art. 60, inciso IX).

Vale ressaltar que embora haja leis e normas que estimulem e direcionam o cumprimento das premissas de acessibilidade turística para pessoas com deficiência ou mobilidade reduzida, ainda:

\begin{abstract}
São encontradas lacunas na acessibilidade universal local e a ineficiência de serviços de acessibilidade que assistam a pessoa com deficiência. A pessoa com deficiência é excluída da integração à vida na cidade e atividades como o turismo se tornam um fardo, para estes indivíduos, devido as muitas limitações encontradas nos destinos e atrativos (MAGALHÃES; SCHUELER, 2020, p. 114).
\end{abstract}

Assim, as dificuldades e limitações de acesso aos bens e serviços turísticos podem gerar sentimentos negativos que desmotivam a escolha por um destino turístico. É importante frisar que os turistas que possuem alguma deficiência ou limitação física, assim como os demais turistas, também viajam pelas mais diversas motivações, desde conhecer novos lugares, novas culturas até mesmo para descansar. Logo, a adequação da infraestrutura dos locais visitados, bem como dos equipamentos turísticos adaptados podem constituir um fator decisivo no momento de escolher um destino turístico e, por conseguinte, atrair mais turistas, pois é comum que os turistas com deficiência viajem acompanhados de outras pessoas.

\title{
3 ACESSIBILIDADE EM CENTROS HISTÓRICOS NO BRASIL
}

De acordo com a Organização Mundial de Saúde (OMS, 2011), mais de um bilhão de pessoas possuem algum tipo de deficiência no mundo. Esses números indicam que uma em cada sete pessoas no mundo se declarou com algum tipo de deficiência. No Brasil, esse quantitativo, segundo os dados do Instituto Brasileiro de Geografia e Estatística - IBGE (2010), chega a 45 milhões, ou seja, 24\% da população brasileira têm alguma deficiência, seja física, auditiva, visual, mental e/ou intelectual.

Apesar dessa estatística, os estudos com dados comprobatórios ainda são minoria, o que contribui para que haja certa invisibilidade dessas pessoas na sociedade. Essa situação consequentemente, reflete no planejamento e na implantação de políticas públicas voltadas para a melhoria da qualidade de vida desse grupo de pessoas. Vale destacar que o exercício pleno e equitativo dos direitos humanos ainda continua sendo pauta nas agendas políticas em níveis mundial e nacional no que concerne aos direitos à educação, ao trabalho, lazer, entre outros. 
No Brasil, no ano de 1985, foi aprovada a primeira norma referente à acessibilidade da pessoa com deficiência - NBR 9050. Essa legislação foi elaborada pelo Comitê Brasileiro de Acessibilidade (ABNT/CB-40), pela Comissão de Edificações (CE40:001.01). Seu conteúdo ficou a cargo dos Comitês Brasileiros (ABNT/CB) e dos Organismos de Normalização Setorial (ABNT/ONS) (ABNT, 2015)

Em decorrência da dinâmica da sociedade, as construções edificadas passaram por modificações significativas e para atender a essa dinâmica a NBR 9050 passou por revisões constantes. Sua última atualização ocorreu em 2015, quando houve a revisão do título, que passou a ser "'Acessibilidade a edificações, mobiliário, espaços e equipamentos', não mais focado nas pessoas com deficiência, mas em uma acessibilidade direcionada para todos, reforçando o conceito de desenho universal4"(PRADO; LOPES; ORNSTEIN, 2010). A norma traz à tona critérios e parâmetros técnicos a serem observados quanto ao projeto, construção, instalação e adaptação, dos meios urbano e rural, de edificações às condições de acessibilidade (ABNT, 2015) para PCD visual, auditiva, mental, física, reduzida e múltipla (NEVES, 2013).

Nesse mesmo ano, foi sancionada a Lei no 13.146, denominada Lei de Inclusão da Pessoa com Deficiência, destinada a assegurar e a promover, em condições de igualdade, o exercício dos direitos e das liberdades fundamentais da pessoa com deficiência, visando a sua inclusão social e cidadania, reafirmando o dever das organizações públicas de promover ações com excelência para esse público específico, em todas as esferas. Quanto à acessibilidade, desenvolveu-se o conceito de desenho universal como "premissa de projeto que visa atender a maior gama possível de variações das características antropométricas e sensoriais da população" (BRASIL, 2015, s.p.), garantindo, assim, o direito de ir e vir e a inclusão de todos. Seus sete princípios baseiam-se em Ribeiro (2014, p. 14-15):

\footnotetext{
1 - Uso equiparável - cada elemento deve ser útil e comercializável às pessoas com habilidades diferenciadas; 2 - Flexibilidade de uso - cada elemento atende a uma ampla gama de indivíduos, preferências e habilidades; 3 - Uso simples e intuitivo - o uso deve ser de fácil compreensão, independentemente da experiência, do nível de formação, do conhecimento do idioma ou da capacidade de concentração do usuário; 4 - Informação perceptível - a comunicação ao usuário deve ser eficaz e as informações necessárias devem estar disponíveis, independentemente de sua capacidade sensorial ou de condições ambientais; 5 - Tolerância ao erro - devem-se minimizar o risco e as consequências adversas de ações involuntárias ou imprevistas; 6 - Baixo esforço físico - cada elemento pode ser utilizado com um mínimo de esforço, de forma eficiente e confortável; 7 - Tamanho e espaço para aproximação e uso - cada elemento deve oferecer espaços e dimensões apropriados para interação, alcance, manipulação e uso, independentemente de tamanho, postura ou mobilidade do usuário.
}

4 Segundo a Norma NBR 9050 (ABNT, 2015), desenho universal corresponde a concepção de produtos, ambientes, programas e serviços a serem utilizados por todas as pessoas, sem necessidade de adaptação ou projeto específico, incluindo os recursos de tecnologia assistiva. 
Dessa forma, as organizações, sejam elas públicas ou privadas, devem desempenhar e almejar $\mathrm{o}$ alcance de tais princípios, com vistas a garantir a acessibilidade de todos os usuários (idosos, gestantes, crianças, pessoas deficientes etc). $\mathrm{O}$ acesso aos equipamentos e aos espaços públicos - como, por exemplo, ruas, calçadas, museus, teatros etc.- apesar de ter sido incluído na pauta das ações públicas, ainda é precário em muitos lugares e constitui fator de limitação à autonomia das PCD, o que, consequentemente, impacta na qualidade de vida e no bem-estar social.

É o caso de algumas cidades históricas brasileiras que ainda não se adequaram à realidade das normativas citadas, apresentando questões históricas, políticas e culturais mal resolvidas, que limitam o acesso universal das pessoas. Os centros históricos, conforme destacam Dischinger, Ely e Piardi (2012), são lugares restritos, de difícil acesso, com sérios impedimentos ou dificuldades originadas de barreiras, que podem ser classificadas como:

\begin{abstract}
[...] arquitetônicas (barreiras de ordem física, nos ambientes externo e interno do equipamento), barreiras na comunicação (de ordem interpessoal, escrita e digital), barreiras atitudinais (falta de conscientização comunitária, com preconceito, criação de estereótipos e discriminação), barreiras metodológicas (métodos e técnicas de estudo, bem como treinamento profissional) e programáticas (são barreiras no contexto das políticas públicas, regulamentos e normas) (NEVES, 2013, p. 22, grifo nosso).
\end{abstract}

Ribeiro (2014, p. 17) destaca que, nos centros históricos, "a mobilidade e a acessibilidade urbana ainda são questões mal resolvidas. Muitos dos obstáculos físicos existentes são resultantes da implantação das cidades no território: topografia com declives acentuados". A isso se agregam as práticas de preservação dos sítios históricos, que tendem a não compatibilizar acessibilidade e mobilidade nas áreas de preservação, mantendo-as incólumes, sem as devidas readequações arquitetônicas, como é o caso de prédios tombados pelo patrimônio histórico que não podem sofrer uma série de alterações (RIBEIRO, 2014). Essa condição os desvaloriza enquanto espaços de amplo acesso e de usufruto pela sociedade local ou por turistas.

Segundo Silva (2006, p.73), com a readequação e a adaptação dos espaços públicos, "aumenta-se a possibilidade de acesso, assegura-se a utilização da edificação, garante-se a conservação e a valorização do patrimônio através do uso". O turismo, por sua vez, ao se apropriar desses espaços e ao utilizar a infraestrutura existente na localidade, pode se tornar um grande potencializador da economia local (DUTRA, 2018).

O bairro da Praia Grande está localizado no Centro Histórico de São Luís, capital do Maranhão, que por sua vez é tombado como Patrimônio Cultural da Humanidade pela UNESCO (Organização das Nações Unidas para a Educação, Ciência e a Cultura) desde o ano de 1997, e dá acesso a diversas casas de cultura, museus, teatros, lojas de artesanato, dentre outros atrativos turísticos, concentrando também a maior movimentação turística da cidade. Nesse sentido, justifica-se a escolha do bairro 
como referencial empírico por concentrar os principais equipamentos turísticos e atrativos históricos e culturais.

\section{PROCEDIMENTOS METODOLÓGICOS}

Com o objetivo de analisar as condições de acessibilidade para cadeirantes em espaços e equipamentos públicos existentes no bairro histórico e turístico Praia Grande, em São Luís, MA, tendo a NBR 9050/2015 como princípio de análise, adotouse, no presente trabalho, o ciclo de pesquisa em três etapas (MINAYO, 1994): fase exploratória, trabalho de campo e análise tratamento dos dados.

Na fase exploratória, buscou-se delimitar e definir o objeto de estudo, tendo sido realizadas pesquisas bibliográfica e documental por meio de materiais, como livros, sites, teses, dissertações e artigos científicos sobre as categorias: acessibilidade, centros históricos e turismo.

Buscou-se também subsidiar a pesquisa a partir da norma NBR ABNT 9050/2015 e relacionando-a com as cinco dimensões de acessibilidade, a saber: barreiras arquitetônicas, barreiras na comunicação, barreiras atitudinais, barreiras metodológicas e programáticas.

Delimitado e definido o objeto de estudo "turismo acessível em centros históricos", a proposta foi lançar um olhar sobre a acessibilidade em um bairro histórico de São Luís/MA, sendo escolhido o bairro da Praia Grande, um dos oito bairros que constituem o centro histórico ludovicense ${ }^{5}$ e o que concentra a maior movimentação de turistas e de equipamentos e serviços turísticos.

Assim, iniciou-se a observação in loco dos espaços urbanos (calçadas, rampas de acesso, sinalização, dentre outros), de forma a verificar se dispõem de arquitetura acessível ou não para a pessoa com deficiência locomotora. Nesse mesmo ínterim, foram aplicados questionários entre os meses de maio e junho de 2019 , em períodos alternados do dia, nas ruas mais frequentadas por turísticas e visitantes do bairro da Praia da Grande, a saber: a Ladeira do Comércio e as Ruas da Estrela e a Portugal, espaços nos quais se concentram importantes atrativos culturais e grande movimentação de turistas.

Os espaços de abordagem foram delimitados devido ao fato de o bairro selecionado concentrar muitas ladeiras e escadarias, o que inviabiliza o acesso do cadeirante. Os questionários continham 10 (dez) perguntas abertas e fechadas, e foram destinados às PCD física (cadeirantes) que transitavam pelas ruas do bairro pesquisado com um universo de oito entrevistados, cadeirantes turistas.

Os dados e as informações recolhidos no campo e na fase exploratória foram ordenados, classificados e analisados, "produzindo o confronto entre a abordagem

5 Bairros que compõem o Centro Histórico de São Luís: Praia Grande, Desterro, Apicum, Belira, Macaúba, Coreia, Centro e Madre Deus. 
teórica anterior e o que a investigação de campo aponta de singular como contribuição" (MINAYO, 1994, p. 26). Os resultados expostos a seguir apresentam a realidade do Bairro da Praia Grande, em São Luís/MA, no que diz respeito à acessibilidade aos cadeirantes nos espaços públicos.

\section{RESULTADOS E DISCUSSÕES}

Aos entrevistados foi perguntado se durante a circulação pelo bairro da Praia Grande as ruas e calçadas são acessíveis, ou seja, se são livres de obstáculos, permitindo o uso para todas as pessoas. Evidenciou-se que a circulação foi considerada inacessível de forma unânime, sendo, portanto, uma dificuldade vivenciada por todos os participantes da pesquisa.

A Ladeira do Comércio, a Rua da Estrela e a Rua Portugal, por serem pavimentadas com paralelepípedos, causam muita trepidação, o que dificulta a fluidez da cadeira de rodas, aumentando o grau de esforço para a locomoção. Um ponto positivo observado pelos pesquisados foi o fato de as ruas não possuírem tráfego de carros, sendo uma área destinada apenas aos pedestres. As calçadas das ruas citadas ainda possuem trechos pavimentados com pedra sabão, do período colonial.

Os entrevistados afirmaram que as calçadas são desniveladas e íngremes, fora dos padrões mínimos de circulação para cadeirantes. Quanto aos aspectos de pavimentação das calçadas, $100 \%$ dos entrevistados consideram o piso irregular e trepidante, com elevado grau de dificuldade para trafegar por elas. Foi sinalizanda, ainda, a existência de desníveis e buracos.

Conforme a NBR 9050/2015, o "fator importante para que a movimentação de pessoas em cadeiras de rodas se dê de forma segura e confortável é a garantia das dimensões mínimas nas áreas de circulação" (ABNT, 2015, s.p.). A possibilidade e a condição de uso dos espaços públicos - como no caso das ruas e das calçadas do Bairro da Praia Grande - com segurança e autonomia estão comprometidas por barreiras arquitetônicas nestas áreas de circulação.

Os entrevistados apontaram que os espaços das calçadas são exíguos e estreitos e não possuem rebaixamento no meio fio. As respostas apresentadas evidenciaram que as dificuldades de percurso estão presentes em todos os âmbitos do local. Embora o bairro pesquisado seja um dos principais atrativos turísticos da cidade de São Luís, e receba turistas de diversas partes Brasil e do mundo, ainda está longe de atender às necessidades do cidadão cadeirante, seja ele morador ou turista.

Questionados sobre as condições adequadas de uso das rampas, a afirmação sobre a imprevisibilidade dessas construções é novamente citada por todos. Foi evidenciada pelos participantes da pesquisa a inexistência ou a inadequação das rampas. Os entrevistados afirmaram que, quando existem, estas rampas são íngremes, isto é, não seguem o padrão determinado pela NBR 9050/2015. Constatouse que a circulação não é acessível e não é garantida do ponto inicial ao destino final, 
posto que as rampas foram mal projetadas ou mal executadas, limitando o acesso do turista/visitante cadeirante, que pode se sentir constrangido por necessitar de ajuda.

Do universo dos entrevistados, $88 \%$ enfatizaram que a circulação com a cadeira de rodas é impossível sem a ajuda de terceiros, visto que os ambientes visitados contam com pouca adaptação para torná-los acessíveis, tanto nas ruas como nos acessos a equipamentos e aos serviços turísticos.

Em síntese, o que se observa é majoritariamente os entrevistados desta pesquisa sentem-se excluídos dos espaços culturais, ou pela ausência de rampas ou por não terem acesso adequado às rampas existentes. Os espaços de cultura, que deveriam unir e integrar, acabam sendo excludentes por limitar o acesso às PCD que são cadeirantes.

Outro item pesquisado foi sobre a existência de elevadores nos locais visitados pelos entrevistados, como museus, teatros e centros culturais. No teatro João do Vale, localizado à Rua da Estrela, apesar de possuir elevador, no momento da pesquisa, este se encontrava em manutenção; além do mais, as áreas de circulação do teatro são estreitas a ponto de, em alguns trechos, não ser possível a passagem de um cadeirante; e na plateia não há locais reservados para cadeirantes, o que está em desacordo com as normas e leis vigentes. A esse respeito, os princípios do desenho universal orientam que todos os ambientes ou espaços construídos, produtos e serviços devem visar a maior abrangência possível de usuários de modo igualitário; adaptável; óbvio; conhecido; seguro; sem esforço e abrangente (ABNT, 2015).

Assim, faz-se necessária a readequação do espaço, desde a instalação (e funcionamento) do elevador, até a adequação dos assentos e das áreas de circulação. Um dos entrevistados relatou que devido ao fato de não haver espaço apropriado para sua cadeira de rodas no teatro teve que assistir a um espetáculo na parte lateral da plateia.

De acordo com Decreto n ${ }^{\circ}$ 9.404/2018, em seu art. 23, os teatros (assim como demais locais de espetáculos, de conferências e similares) devem reservar espaços livres para pessoas em cadeira de rodas, e assentos para PCD ou com mobilidade reduzida (BRASIL, 2018, s.p.). Além disso, ao serem instalados e sinalizados, os espaços reservados devem seguir os requisitos estabelecidos nas normas técnicas de acessibilidade da Associação Brasileira de Normas Técnicas - ABNT (BRASIL, 2018, s.p.). Vale registrar que o Museu de Artes Visuais, localizado à Rua Portugal, passou recentemente por reforma e já conta com acesso aos espaços de exposição por meio de elevador.

Também é oportuno salientar que os casarões antigos e tombados pelo IPHAN possuem algumas barreiras no que se refere às reformas destes espaços. Contudo, o órgão regulamenta a lei que sanciona e dá outras providências para transformação desses espaços e para adaptações de equipamentos urbanos existentes. Para que essas mudanças no patrimônio arquitetônico sejam garantidas, o Estado deve assumir a responsabilidade pela fiscalização e pela efetivação dos direitos da PCD, assegurando que as transformações aconteçam e que as edificações sejam 
adaptadas de acordo com os parâmetros do desenho universal, de modo a contemplar a diversidade do ser humano.

Nesse sentido, destaca-se que a maioria das áreas analisadas não está em consonância com as necessidades dos turistas cadeirantes, conforme apresentado no quadro 1.

\section{QUADRO 1 - NÃO CONFORMIDADES ÁREAS DO CENTRO HISTÓRICO}

\begin{tabular}{|c|c|}
\hline Locais & Não conformidades \\
\hline Ruas & Pavimentadas com paralelepípedos \\
\hline Calçadas & $\begin{array}{l}\text { Pavimentadas de pedra sabão; desniveladas e íngremes; fora dos pa- } \\
\text { drões mínimos de circulação para cadeirantes }\end{array}$ \\
\hline Uso de rampas & $\begin{array}{c}\text { Inexistência ou inadequação das rampas. Estas rampas são íngremes, } \\
\text { mal projetadas, limitando o acesso do turista/visitante aos locais visita- } \\
\text { dos }\end{array}$ \\
\hline $\begin{array}{l}\text { Edificações e } \\
\text { equipamentos } \\
\text { urbanos }\end{array}$ & $\begin{array}{l}\text { Elevador do museu encontrava em manutenção; áreas de circulação } \\
\text { estreitas; na plateia não há locais reservados para cadeirantes }\end{array}$ \\
\hline
\end{tabular}

Conforme a NBR 9050, as ruas e calçadas do Centro Histórico de São Luís (que são pavimentadas com paralelepípedos e pedra sabão) não seguem o quesito de piso sem desníveis, que garanta o livre acesso, ou seja, "faixa livre ou passeio [... deve ser livre de qualquer obstáculo, ter inclinação transversal até $3 \%$, ser contínua entre lotes e ter no mínimo 1,20 m de largura e 2,10 m de altura livre" (ABNT, 2015, s.p.).

Com relação às rampas, o ideal é que sejam definidos os limites máximos de inclinação, os desníveis a serem vencidos e o número máximo de segmentos. No caso das rampas encontradas no Centro Histórico de São Luís, observou-se que muitos dos estabelecimentos não dispunham de rampas e, quando possuíam, não respeitavam os limites de inclinação. Assim, a NBR 9050 direciona que:

Em edificações existentes, quando a construção de rampas nas larguras indicadas ou a adaptação da largura das rampas for impraticável, as rampas podem ser executadas com largura mínima de 0,90m e com segmentos de no máximo $4,00 \mathrm{~m}$ de comprimento, medidos na sua projeção horizontal (NBR, 2015, s.p).

Por fim, ao que se refere às edificações e equipamentos urbanos, os espaços como teatros, até possuíam elevadores, mas estavam em manutenção. Em certos trechos, uma PCD não conseguiria circular devido a largura dos espaços estreitos ou estacionar sua cadeira de rodas na plateia, por não ter vaga. A norma determina que 
as larguras mínimas para corredores em edificações e equipamentos urbanos devem seguir os seguintes padrões:

a) 0,90 m para corredores de uso comum com extensão até $4,00 \mathrm{~m}$; b) 1,20 $\mathrm{m}$ para corredores de uso comum com extensão até 10,00 m; e 1,50 m para corredores com extensão superior a 10,00 m;c) 1,50 m para corredores de uso público;d) maior que 1,50 m para grandes fluxos de pessoas (ABNT, 2015, s.p).

E caso não se consiga adequar os corredores às métricas estabelecidas, é possível implementar bolsões de retorno com dimensões que permitam a manobra completa de uma cadeira de rodas. Assim, as informações acima revelam que a maioria dos locais avaliados não foi considerado acessível, existindo várias barreiras físico-arquitetônicas e que são enfatizadas pelos próprios usuários.

Os entrevistados apontaram a existência de barreiras físico-espaciais ou arquitetônicas nos locais visitados. Os itens observados foram em relação às rampas, corredores, portas, sanitários e móveis, como mostra o gráfico 1, abaixo:

\section{GRÁFICO 1 - QUANTO AOS ITENS CITADOS, HAVIA ACESSIBILIDADE AOS ESPAÇOS PÚBLICOS VISITADOS?}

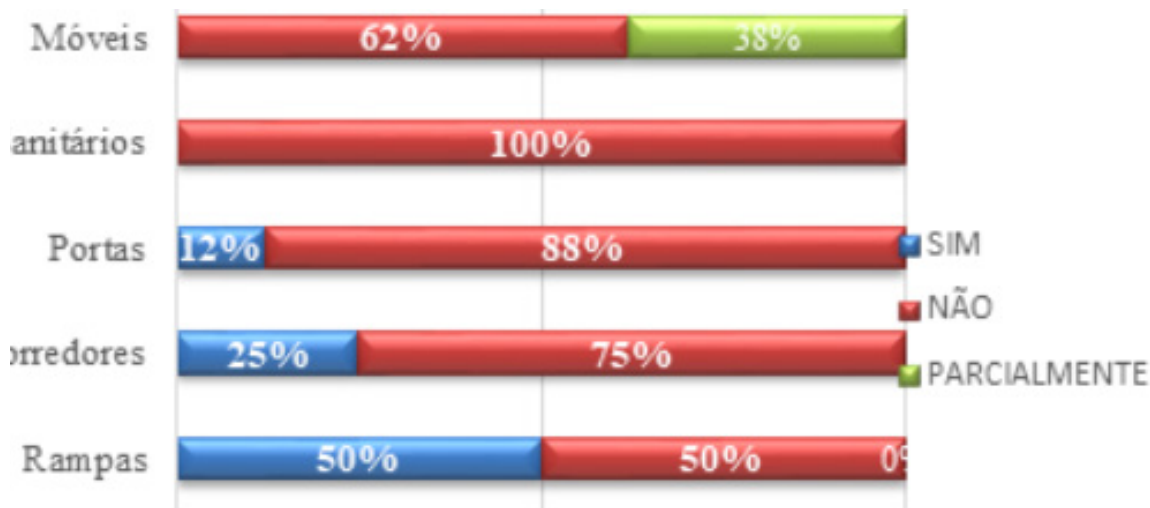

FONTE: Os autores (2019)

A pesquisa revela que a maioria dos itens avaliados não foi considerado acessível, principalmente os sanitários, com 100\% de inacessibilidade. Isto posto, fica evidente que ainda necessitam ser realizadas várias adaptações e readequações nos equipamentos que fazem parte da infraestrutura dos espaços públicos na Praia Grande para que o bairro se torne acessível para PCD, etc.

Entende-se que, por se tratar de um local histórico e tombado, o bairro precisa atender a critérios de uma legislação específica, mas, conforme os resultados da pesquisa demonstram, são muitos os obstáculos físicos existentes que ainda precisam 
ser superados a fim de conciliar acessibilidade e mobilidade às áreas de preservação, permitindo, conforme Silva (2006, p.73), a possibilidade de acesso e a utilização da edificação, bem como "a conservação e valorização do patrimônio através do uso".

Outro ponto primordial para a garantia da acessibilidade a pessoas com qualquer tipo de deficiência é a comunicação, seja ela de ordem interpessoal, escrita e digital. Por isso, entende-se a sinalização como parte chave da comunicação e que pode alterar diretamente os objetivos propostos pelos mobiliários urbanos, seja por possuir sinalização completa ou por sua inexistência.

Segundo a NBR 9050/2015, a sinalização deve "ser autoexplicativa, perceptível e legível para todos (ABNT, 2015, s.p.). No bairro da Praia Grande, as ruas pesquisadas apresentaram placas sinalizando os monumentos históricos e culturais, mas não foram identificadas sinalizações em relação aos locais acessíveis, de forma autoexplicativa, perceptível e legível para todos, em consonância com a exigência da norma referenciada.

Para fins de compreensão, a NBR 9050, no item 5.3, apresenta o símbolo internacional de acesso e aponta que ele deve ser utilizado para indicar a acessibilidade nos serviços, espaços, edificações, mobiliários e equipamentos urbanos onde existem elementos acessíveis ou utilizáveis por PCD ou com mobilidade reduzida. Quanto aos locais visitados, os entrevistados apontaram que não havia sinalização de rampas, elevadores e acessos verticais e horizontais. Alguns espaços públicos, como o teatro e os museus, apresentaram elementos de sinalização essenciais, como informações de sanitários e rotas de fuga.

Para uma sinalização eficaz é essencial que exista placas com informação em locais visíveis ao público, principalmente em entradas, áreas e vagas de estacionamento de veículos, áreas de embarque e desembarque de passageiros com deficiência e sanitários. Embora sejam primordiais os informativos para auxiliar na seguridade e na autonomia dos cadeirantes em um trajeto, as respostas apresentadas contemplaram negativamente este quesito, indicando que há sinalização ineficiente nos espaços públicos percorridos do bairro em análise.

As barreiras que o Centro Histórico de São Luís, especialmente o Bairro da Praia Grande, apresenta estão para além das dificuldades físicas e comunicacionais. 75\% dos entrevistados se sentiram constrangidos por não poderem acessar sozinhos o espaço público, bem como por dependerem de terceiros para realizar essa ação. Essas barreiras surgem por conta da falta de acesso e da falta de comunicação, e afetam as pessoas com deficiência, causando insegurança e, muitas vezes, desistências, a ponto de evitarem determinados percursos.

O desconhecimento ou mesmo o despreparo de profissionais que trabalham direta e indiretamente com o Turismo e até mesmo da própria comunidade geram entraves que dificultam o "acesso, a permanência, o manuseio, o livre deslocamento de pessoas com mobilidade reduzida em locais de uso comum ou qualquer outra atividade social que queiram realizar, participar, presenciar ou contemplar" (NEVES, 2013, p. 30). 
Segundo Neves (2013), para o desenvolvimento do turismo inclusivo, uma série de mudanças políticas deve ser promovida, de maneira a democratizar a experiência turística. Dessa forma, as barreiras também podem ser políticas, imperceptíveis, embutidas em políticas públicas que dificultam ou limitam o acesso das pessoas cadeirantes. É o caso das barreiras programáticas disseminadas em leis, portarias, decretos e regulamentos que propagam a exclusão.

De acordo com o depoimento de um dos entrevistados, a legislação existe, mas não é posta em prática, o que limita os direitos das PCD: "Todos, pela legislação, têm o direito de ir e vir, mas isso é banido de nós. É muito triste, mas, infelizmente, é a condição que nós temos. Tenho a impressão de que todos são lembrados, menos uma pessoa com deficiência. É difícil!” (Entrevistado 1).

O direito de se locomover pela cidade é de todos os cidadãos. Todavia, isso não é priorizado na área do centro histórico de São Luís alcançada pela pesquisa, pois ruas sinuosas, pavimentadas com paralelepípedos, calçadas estreitas, desniveladas, com a presença de ladeiras e escadarias, dificultam o acesso e a circulação das pessoas cadeirantes.

A entrevistada 2 propôs sugestões de melhorias para facilitar o acesso dessas pessoas, como: "poderia melhorar a infraestrutura das ruas, colocando uma calçada plana sem os ladrilhos. E nas ruas com escadas, possuir também as rampas para dar acesso à pessoa com deficiência" (Entrevistada 2). Essa sugestão também é prevista por Ribeiro (2014, p. 69), quando apresenta, em sua obra, os planos de mobilidade e acessibilidade apoiados pelo IPHAN "para os conjuntos urbanos protegidos dos municípios de Laguna (SC), Paranaguá (PR), São Francisco do Sul (SC) e Ouro Preto (MG)". Assim, nesses locais foram analisadas as peculiaridades a partir do enfoque das propostas e as possibilidades de soluções para problemas distintos detectados nas cidades.

No município de Laguna (SC), por exemplo, a proposta no plano foi a implantação do conceito de "espaço compartilhado". Em Ouro Preto, a proposta estava direcionada para a oferta de sistema de transporte, que trouxesse baixo impacto ambiental, bem como o estabelecimento de nova política de estacionamentos, com foco nos moradores e usuários do núcleo histórico, entre outras.

Dessa maneira, é possível vislumbrar a compatibilização entre a mobilidade e a acessibilidade urbanas e a preservação de áreas de interesse cultural a partir de

6 Segundo Ribeiro (2014, p.70), o conceito de espaço compartilhado foi "desenvolvido pelo holandês Hans Monderman, em 1969, com o objetivo de remover a segregação por meio da oferta de espaços compartilhados e adoção de velocidades compatíveis. Essa solução implica na conscientização dos condutores de veículos quanto à fragilidade dos pedestres, para que adotem velocidades compatíveis com as áreas em que trafegam. Para ser implementado tal conceito, muito utilizado em cidades europeias, é necessária ampla campanha educacional, a fim de que a convivência entre pedestres, ciclistas, motoristas e pessoas com deficiência possa ocorrer de maneira harmoniosa". 
experiências exitosas em outras localidades, adaptando-as à realidade do centro histórico da capital maranhense.

\section{CONSIDERAÇÕES FINAIS}

Acessibilidade é um tema discutido em diversos setores e abrange um conjunto de fatores que cooperam na promoção e na garantia de acesso a todos os lugares para todas as pessoas, sejam elas PCD ou não. No turismo, é essencial que os destinos e os equipamentos turísticos que oferecem determinado produto ou serviço estejam em funcionamento, e que contemplem o ser humano de modo geral.

Considerando o que regem as normas e as leis mencionadas, os espaços construídos ou reformados devem oferecer condições de acessibilidade aos cadeirantes, valendo-se, para tanto, do uso do desenho universal, que se torna importante por minimizar as diferentes barreiras existentes (arquitetônicas, comunicação, atitudinais, metodológicas e programáticas).

Contudo, a apresentação dos dados obtidos expõe que há muito a ser adequado e adaptado no bairro da Praia Grande para que o visitante cadeirante consiga circular com segurança e autonomia. A pesquisa demonstrou que o acesso a determinados locais é limitado para cadeirantes, principalmente por conta de barreiras arquitetônicas, devido à condição biológica que os impedem ou limitam. Embora os centros históricos tenham especificidades que fazem parte de um patrimônio cultural material e que precisam ser preservadas, faz-se necessária a elaboração de novos projetos inclusivos para o Bairro em questão.

Não basta projetar rampas com inclinações adequadas ou implantar elevadores com cabines bem dimensionadas, também é preciso considerar o mobiliário urbano, as instalações de iluminação, o sistema de informação, de comunicação, de segurança e de transporte. Deve-se ter a clareza de que nem todos os problemas serão resolvidos pela norma, mas por um conjunto de esforços que incluem a transposição de barreiras atitudinais, ou seja, de comportamentos que impedem ou dificultam a interação da pessoa com deficiência. Na prática, essas barreiras são mais difíceis de transpor que as barreiras físicas.

Diante dos comentários finais, propõem-se melhorias na infraestrutura das ruas para efetivar o acesso da pessoa com deficiência (cadeirante) ao Bairro da Praia Grande, ou seja, mudanças que viabilizem outros meios de acessibilidade além dos já existentes, isso porque que eles não contemplam minimamente as condições básicas de uso. Além disso, as barreiras físicas ensejam outros tipos de obstáculos (de comunicação, metodológicas e programáticas) que impedem a pessoa com deficiência de ter uma vida socialmente ativa, o que gera a frustração de ter seus direitos desrespeitados. Assim, a visibilidade de todos os grupos existentes na sociedade e sua real valorização tem implicação direta no bem-estar geral da comunidade, uma vez que o sentimento de pertencimento é real e seu acesso ao mundo externo também. 
No processo de coleta de dados, importa mencionar as limitações que a pesquisa pode sofrer quanto à possibilidade de expressão inexata de alguns entrevistados frente à realidade do objeto estudado e, também, a dificuldade em encontrar o público alvo da pesquisa na área investigada. Por outro lado, considerou-se bastante positiva a receptividade das pessoas que participaram e a compreensão quanto à contribuição que o estudo pode proporcionar para a melhoria da acessibilidade em atrativos turísticos na cidade de São Luís/MA.

Ademais, orienta-se o desenvolvimento de mais estudos relacionados à temática, assim como ao campo da pesquisa, com vistas a reunir esforços no avanço da produção, da publicização de trabalhos relacionados ao turismo e a acessibilidade, pois ainda há muito a se construir e avançar na produção desta temática. E quanto mais base de informações e conhecimento houver, melhor será para o avanço de uma sociedade mais inclusiva e, portanto, mais acessível para todas as pessoas.

\section{REFERÊNCIAS}

ASSOCIAÇÃO BRASILEIRA DE NORMAS TÉCNICAS (ABNT). NBR 9050: 2015 Acessibilidade a edificações, mobiliário, espaços e equipamentos urbanos. Rio de Janeiro: ABNT, 2015. Disponível em: https://www.ufrgs.br/incluir/wp-content/ uploads/2017/07/Acessibilidade-a-edifca\%C3\%A7\%C3\%B5es-mobili\%C3\%A1rioespa\%C3\%A7os.-PDF1.pdf. Acesso em: 22 jan. 2020.

BRASIL. Lei $\mathbf{n}^{\circ}$. 13.146, de 06 de julho de 2015. Institui a Lei Brasileira de Inclusão da Pessoa com Deficiência (Estatuto da Pessoa com Deficiência). Brasília, DF, 2015. Disponível em: http://www.planalto.gov.br/ccivil_03/_Ato2015-2018/2015/Lei/ L13146.htm. Acesso em: 22 fev. 2020.

BRASIL. Decreto n. 9.404, de 11 de junho de 2018. Altera o Decreto $n^{\circ} 5.296$, de 2 dezembro de 2004, para dispor sobre a reserva de espaços e assentos em teatros, cinemas, auditórios, estádios, ginásios de esporte, locais de espetáculos e de conferências e similares para pessoas com deficiência. Brasília, DF, 2015. Disponível em: http://www.planalto.gov.br/ccivil_03/_Ato2015-2018/2018/Decreto/ D9404.htm. Acesso em:22 fev. 2020.

CARMO, C. M. Grupos minoritários, grupos vulneráveis e o problema da (in) tolerância: uma relação linguístico-discursiva e ideológica entre o desrespeito e a manifestação do ódio no contexto brasileiro. Revista do Instituto de estudos Brasileiros, n. 64, p. 201-223, 2016. Disponível em: http://www.scielo.br/pdf/rieb/ n64/0020-3874-rieb-64-0201.pdf. Acesso em: 22.03.2020.

COELHO, M. F.; GUIMARÃES, M. P. Turismo Inclusivo e Lazer em Espaços Públicos. In: SEMINÁRIO DA ASSOCIAÇÃO NACIONAL PESQUISA E PÓS-GRADUAÇÃO EM TURISMO, 9, 2012, São Paulo, Anais..., São Paulo, 2012. Disponível em: https:// www.anptur.org.br/anais/anais/files/9/31.pdf. Acesso em: 09 dez. 2020. 
COSTA, S. M. B. Dignidade Humana e Pessoa com Deficiência: Aspectos Legais e Trabalhistas. São Paulo: São Paulo, 2008.

DIAS, W. P. S. O discurso da inclusão em documentos oficiais: condições de aparecimento do tradutor e intérprete de libras/língua portuguesa. In: CLEMENTE, J. C.; FRAGA, L. M.; MACHADO, M. C. C. (Orgs.). Educação especial no Maranhão: o caminhar da inclusão. São Paulo: Editora Garcia Edizioni, 2019.

DISCHINGER, M.; ELY, V. H. M. B.; PIARDI, S. M. D. G. Promovendo acessibilidade espacial nos edifícios públicos: Programa de Acessibilidade às Pessoas com Deficiência ou Mobilidade Reduzida nas Edificações de Uso Público. Florianópolis: MPSC, 2012. Disponível em: https://www.mpam.mp.br/attachments/article/5533/ manual_acessibilidade_compactado.pdf. Acesso em: 22 jan. 2020.

DUTRA, R D. Olhos que tocam o chão, corpos na contramão: $P C D$, acessibilidade e mobilidade no centro histórico da cidade de Goiás. Dissertação (Mestrado em Geografia) - Universidade Federal de Goiás, Campus SamambaiaGoiânia, Goiânia, GO, 2018. Disponível em: https://repositorio.bc.ufg.br/tede/ bitstream/tede/9259/5/Disserta\%c3\%a7\%c3\%a3o\%20-\%20Renata\%20Dias\%20 Dutra\%20-\%202018.pdf. Acesso em: 22 jan. 2020.

GIRLE, R. Possible Worlds. Montreal: McGill-Queen's, 2003.

INSTITUTO BRASILEIRO DE GEOGRAFIA E ESTATÍSTICA (IBGE). Perfil regional. Disponível em: http://www.ibge.org.br/. Acesso em: 25.03.2020.

KUSHANO, E. S.; ALMEIDA, W. G. Inclusão social, cidadania e Turismo: uma investigação sobre a existência de serviços adaptados às pessoas com necessidades especiais nos meios de hospedagem da região metropolitana de Curitiba. Revista Brasileira de Pesquisa em Turismo, v. 2, n. 4, p. 88-101, 2008. Disponível em: https://rbtur.org.br/rbtur/article/view/119/118. Acesso em: 22 fev. 2020.

MACEDO, M. G. M. Acessibilidade no turismo: serviços e equipamentos turísticos para as pessoas com deficiência na avenida beira mar em Fortaleza. Dissertação (Mestrado Profissional em Gestão de Negócios Turísticos). Universidade Estadual do Ceara, Centro de Estudos Sociais Negócios Turísticos, Fortaleza, 2017. Disponível em: http://www.uece.br/mpgnt/dmdocuments/mariadagloriamonteiro.pdf. Acesso em: 04.02.2020.

MAGALHAES, B. S.; SCHULER, A. S. Turismo na cidade do Rio de Janeiro e a motivação neoliberal no desenvolvimento da acessibilidade universal. Turismo e Sociedade, v. 13, n. 2, p. 107-125, maio-agosto de 2020. Disponível em: https:// revistas.ufpr.br/turismo/article/view/69515/42333. Acesso em: 06 fev. 2021. 
MAZZOTTA, M. J. S.; D’ANTINO, M. El. F. Inclusão social de pessoas com deficiências e necessidades especiais: cultura, educação e lazer. Saúde Sociedade, São Paulo, v. 20, n. 2, p. 377-389, 2011. Disponível em: http://www.scielo.br/scielo. php?script=sci_arttext\&pid=S0104-12902011000200010\&lng=en\&nrm=iso. Acesso em: 07 dez. 2020.

MICHAELIS. Dicionário da língua portuguesa. São Paulo: Melhoramentos, 2020. Disponível em: https://michaelis.uol.com.br/. Acesso em: 22 mar. 2020.

MINAYO, M. C. S. Ciência, técnica e arte: o desafio da pesquisa social. In: DESLANDES, S. F.; NETO, O. C.; GOMES, R.; MINAYO, M. C. S. (Orgs.). Pesquisa social: teoria, método e criatividade. 18. ed. Petrópolis: Vozes, 1994.

NEVES, T. R. Turismo e acessibilidade: um estudo nos equipamentos turísticos natalenses, Aquário Natal e Fortaleza dos Reis Magos com base na Associação Brasileira de Normas Técnica (ABNT). Monografia (Graduação em Turismo) - Universidade Federal do Rio Grande do Norte. Centro de Ciências Sociais Aplicadas. Departamento de Turismo. Natal, RN, 2013. Disponível em: http://arquivos.info.ufrn.br/arquivos/2014212184f0e7194868733c486f1e84e/ TONDERSON_RIBEIRO_NEVES_TURISMO_E_ACESSIBILIDADE_UM_ESTUDO_ NOS_EQUIPAMENTOS.pdf. Acesso em: 22 jan. 2020.

ORGANIZAÇÃO MUNDIAL DA SAÚDE (OMS). Sumário - Relatório Mundial sobre a Deficiência. Tradução Secretaria de Estado dos Direitos da Pessoa com Deficiência de São Paulo. São Paulo, 2011. Disponível em: https:// apps.who.int/iris/bitstream/handle/10665/70670/WHO_NMH_VIP_11.01_por. pdf;jsessionid=E1BD7BD6C3ECD30335EF0498328C0299? sequence=9. Acesso em: 21 fev. 2020.

PEREIRA, M. Turismo e inclusão social: uma avaliação acerca da acessibilidade aos portadores de necessidades físicas e visuais nos equipamentos turísticos de Belém/ PA. Caderno Virtual de Turismo, Rio de Janeiro, v. 11, n. 2, p. 253-266, 2011. Disponível em: http://www.ivt.coppe.ufrj.br/caderno/index.php/caderno/article/ view/660/294. Acesso em: 04 abr. 2020.

PRADO, A. R. A.; LOPES, M. E.; ORNSTEIN, S. W. Apresentação: Trajetória da Acessibilidade no Brasil. In: PRADO, A. R. A.; LOPES, M. E.; ORNSTEIN, S. W. (Org.). Desenho universal: caminhos da acessibilidade no Brasil. São Paulo: Annablume, 2010.

RIBEIRO, S. B. (Org.). Mobilidade e acessibilidade urbana em centros históricos. Cadernos técnicos, 9. Brasília: Iphan, 2014. Disponível em: http://portal.iphan.gov. br/uploads/publicacao/CadTec9_CadernoAcessibilidade_m.pdf. Acesso em: 22 fev. 2020. 
SILVA, L. M. O estranhamento causado pela deficiência: preconceito e experiência. Revista Brasileira de Educação, v. 11, n. 33, 2006. Disponível em: http://www. scielo.br/pdf/rbedu/v11n33/a04v1133.pdf. Acesso em: 15 jan. 2020.

SMITH, M.; AMORIM, E.; SOARES, C. O turismo acessível como vantagem competitiva: implicações na imagem do destino turístico. PASOS. Revista de Turismo y Patrimonio Cultural, v. 11, n. 3, 2013, p. 97-103. Disponível em: https:// www.redalyc.org/pdf/881/88128048010.pdf. Acesso em: 22 mar. 2020.

Recebido em: 15-04-2020.

Aprovado em: 06-02-2021. 
$S$ 